University of Rhode Island

DigitalCommons@URI

Open Access Master's Theses

2014

\title{
ANTICIPATORY SOCIAL ANXIETY AND ALCOHOL USE: AN ECOLOGICALLY VALID LABORATORY EXPERIMENT
}

Michael Bernstein

University of Rhode Island, mbernstein11@my.uri.edu

Follow this and additional works at: https://digitalcommons.uri.edu/theses

\section{Recommended Citation}

Bernstein, Michael, "ANTICIPATORY SOCIAL ANXIETY AND ALCOHOL USE: AN ECOLOGICALLY VALID LABORATORY EXPERIMENT" (2014). Open Access Master's Theses. Paper 319.

https://digitalcommons.uri.edu/theses/319

This Thesis is brought to you for free and open access by DigitalCommons@URI. It has been accepted for inclusion in Open Access Master's Theses by an authorized administrator of DigitalCommons@URI. For more information, please contact digitalcommons-group@uri.edu. 


\title{
ANTICIPATORY SOCIAL ANXIETY AND ALCOHOL USE: AN ECOLOGICALLY VALID LABORATORY EXPERIMENT \\ BY \\ MICHAEL BERNSTEIN
}

\begin{abstract}
A MASTER'S THESIS SUBMITTED IN PARTIAL FULLFILLMENT OF THE REQUIREMENTS FOR THE DEGREE OF MASTERS OF ARTS

IN

BEHAVIORAL SCIENCE
\end{abstract}

UNIVERSITY OF RHODE ISLAND

2014 
MASTER OF BEHAVIORAL SCIENCE THESIS

OF

MICHAEL BERNSTEIN

APPROVED:

Thesis Committee:

Major Professor

Mark Wood

Katherine Branch

Mark Robbins

Nasser H. Zawia

DEAN OF THE GRADUATE SCHOOL

UNIVERSITY OF RHODE ISLAND

2014 


\begin{abstract}
Research has yielded mixed findings on the relation between social anxiety and alcohol use, although no laboratory studies on this topic have been conducted in naturalistic drinking settings. The current study examined the effect of an anticipatory social anxiety manipulation, as well as trait social anxiety, on "alcohol" consumption in a bar-laboratory. We also sought to validate a new placebo alcohol administration procedure. Fifty-four same-sex groups of 2-3 participants and one confederate arrived to the laboratory for a study that ostensibly examined the effect of alcohol use on language fluency. After completing survey questions, participants in the social anxiety condition were told the language fluency portion would consist of giving a five-minute video recorded speech to someone of the opposite sex about how to impress a person on a date. Those in the control group were informed they would have to read a poem to themselves. Before their alleged fluency task, participants were allowed to consume a variety of mixed drinks $a d$ lib in a bar laboratory. No beverages actually contained alcohol, but a number of steps were taken to increase the perception that alcohol was being used. Although the social anxiety induction was successful, neither state social anxiety, trait social anxiety, nor the state by trait social anxiety interaction predicted laboratory alcohol consumption in a multi-level model controlling for a substantial group effect. However, this procedure was highly successful in convincing mostly underage participants they were drinking real alcohol. Findings are considered in light of substantive questions pertaining to the social anxiety manipulation, and methodological considerations relating to placebo alcohol believability.
\end{abstract}




\section{ACKNOWLEDGEMENTS}

I would like to thank my advisor, Mark Wood, for going beyond the duties required by a major professor, and being invested in this project from beginning to end. In addition to our (often lengthy) weekly meetings, Dr. Wood helped support the project monetarily, and was always available to discuss the many time-sensitive issues that inevitably arose.

This study would not be possible without the help of the following undergraduate Research Assistants, who devoted a great deal of time to learning, practicing, and ultimately delivering a very difficult experimental protocol: Sara Atash, Alexander Bethune, Samantha Dubois, Lauren Erickson, Ashley Hebert, Gina Kinan, Amanda Lampe, Chelsea Martini, and Ariana Wakeman. I am also grateful for the work of undergraduate Sara Balestrieri, who helped schedule sessions, and graduate student Grayson Baird for his methodological expertise.

Finally, I would like to thank the Behavior Change Research Center for letting me use a portion of their space as the bar-laboratory. 


\section{PREFACE}

This thesis is written according to the guidelines of the University of Rhode Island graduate school. It also follows the format of APA version 6 for all instances that do not conflict with graduate school guidelines. 


\section{TABLE OF CONTENTS}

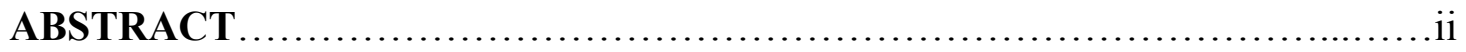

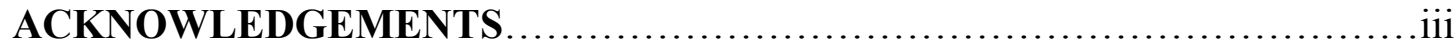

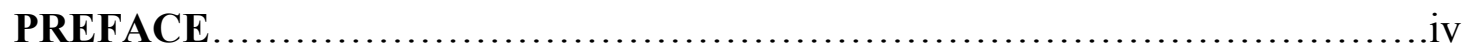

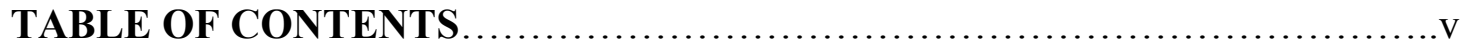

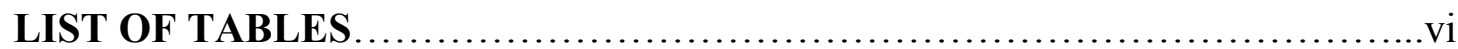

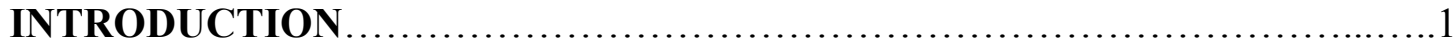

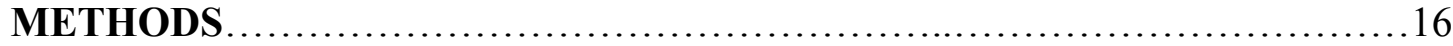

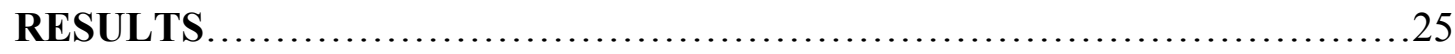

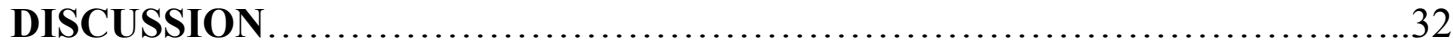

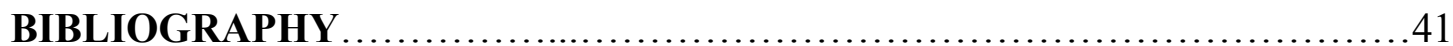




\section{LIST OF TABLES}

TABLE

PAGE

Table 1. Bivariate Correlations.............................................. 30

Table 2. Comparison of Participant Characteristics Across Conditions.................31 


\section{INTRODUCTION}

Rates of alcohol use and misuse vary according to a number of key demographic variables, such as age. Epidemiological research indicates that people in their late teens and early twenties are more likely than any other age group to engage in heavy episodic drinking (Arnett, 2000; Johnston, O’Malley, Bachman, \& Schulenberg, 2012). Among emerging adults (18-25 years old), full-time college students drink more than their non-college counterparts (Johnston et al.), placing this group at the greatest risk of acute alcohol-related problems. The extent of excessive consumption among college students and non-college attending age peers has provided the impetus for a great deal of research on the etiology of alcohol use and misuse.

\section{Etiological Research}

Broadly speaking, etiological work on alcohol use and misuse has utilized two approaches. The first is survey research, where participants complete questionnaires on individual-difference variables as well as report their alcohol use and/or alcoholrelated consequences. This correlational method is most common for both crosssectional and longitudinal designs. The second approach entails studying alcohol use in a laboratory setting. Although this can be challenging with respect to successfully manipulating and measuring variables of interest, laboratory studies enable researchers to make causal inferences not possible with correlational research. In these studies, alcohol consumption may be manipulated as an independent variable or assessed as a dependent variable (for a review, see Plebani et al., 2012). Although the current study 
utilizes a laboratory design, we ${ }^{1}$ first briefly review etiological survey research on the relation between alcohol use, motivations to drink, and personality that informs the current research prior to discussing laboratory studies in greater depth.

\section{Motivation for Alcohol Use and Misuse}

Drawing on the principles of positive and negative reinforcement, Cox and Klinger (1988) proposed a taxonomy of drinking motives. They posit that enhancing positive affect or relieving negative affect are two key reasons for people's decision to drink. An example of the former would be consuming alcohol on an enjoyable night with friends to further enhance a convivial social experience. Drinking to relieve negative affect, on the other hand, could involve drinking alcohol after a situation that causes discomfort, anger, or other negative emotions. In line with this reasoning, Cooper (1994) identified coping as a stable drinking motive that predicts alcohol use and, particularly, alcohol-related consequences. Drinking to reduce stress is higher among current college attendees, relative to those who graduated in the past 1-13 years (Perkins, 1999). Thus, this aspect of relief drinking is a common motivation for college student drinkers, and experimental research is needed to further understand stress-related alcohol use. It has been hypothesized that stress-induced drinking may be more pronounced among individuals high in social anxiety or neuroticism more generally (Higgins \& Marlatt, 1975; Kidorf \& Lang, 1999; Terlecki, Buckner, Larimer, \& Copeland, 2001). Accordingly, we briefly review studies examining relations between these traits and alcohol use and misuse next.

\footnotetext{
1 "We" is used throughout this thesis, because the project was done collaboratively between the student (Mike Bernstein) and advisor (Mark Wood). This is consistent with APA version 6 guidelines, which is being used for formatting (see preface).
} 


\section{Personality and Alcohol Use and Misuse}

Neuroticism/Negative affect. A review of research on personality - alcohol use relations concluded there was strong evidence for an association between neuroticism and alcohol use disorders with some studies suggesting that neuroticism is related to alcohol involvement at sub-clinical levels (Sher, Trull, Bartholow, \& Vieth, 1999). Subsequent work provided further support for a positive association between neuroticism and alcohol use in a non-clinical sample. Specifically, in a longitudinal investigation that followed college freshman for over 16 years, increases in neuroticism were positively related to increases in problematic alcohol use. This association existed when assessing neuroticism with both the "Big Three" and "Big Five" questionnaires, and after controlling for important covariates such as marriage and parenthood that are associated with "maturing out" of problematic drinking (Littlefield, Sher, \& Wood, 2009, 2010). In a meta-analysis on the relation between personality and alcohol use, Malouff, Thorsteinsson, Rooke, and Schutte (2007) found a significant small to medium positive correlation of $r=.15$ between neuroticism and alcohol involvement in over 20 studies with nearly 8,000 participants.

Social anxiety. Studies examining lower order components of broad-band personality constructs suggest that social anxiety is a key facet of the general construct of neuroticism (Naragon-Gainey \& Watson, 2011). This is consistent with a factor analytic study that observed anxiety loads highly onto the negative affect dimension of personality, using five- and three-factor models (Zuckerman, Kuhlman, \& Camac, 1988). 
Given the interrelatedness between these constructs, it is curious that the association between alcohol use and social anxiety appears to vary from those observed for more general neuroticism - alcohol use relations. Research in this area is mixed with some studies finding a negative association between alcohol outcomes and social anxiety (Clerkin \& Barnett; 2012; Ham, Bonin, \& Hope, 2007; Ham \& Hope, 2005; Norberg, Norton, \& Oliver, 2009), and others observing no relation (Buckner, Schmidt, \& Eggleston, 2006; Ham, Carrigan, Moak, \& Randall, 2005; Ham \& Hope, 2006). In a recent meta-analysis (Scrhry \& White, 2013) across 44 studies of 18-24 year old college students, a small, negative association was observed between social anxiety and alcohol quantity $(r=-.07)$, alcohol frequency $(r=-.10)$, and heavy episodic drinking $(r=-.08)$. However, there was a very modest positive association between social anxiety and alcohol-related problems $(r=.05)$.

\section{Laboratory Studies of Alcohol Consumption}

As noted, laboratory studies administering alcohol can be divided into those with consumption as an independent or dependent variable. One example of the former is giving real or placebo alcohol to participants and measuring the effect of actual versus expected alcohol consumption on aggressive behavior (Bushman, Giancola, Parrott, \& Roth, 2012). Conversely, some studies using alcohol as a dependent variable have examined the degree to which manipulated variables affect $a d$ lib alcohol consumption. These include manipulations of negative emotions such as: the threat of shock (Higgins \& Marlatt, 1973), receiving negative feedback for one's social ability (Holroyd, 1978) or intelligence (Hull \& Young, 1983), talking to an insulting confederate (Marlatt, Kosturn, \& Lang, 1975), trying to solve an un-solvable 
anagram (Morrison, Noel, \& Ogle, 2012), and interacting with a difficult child (Lang, Pelham, Johnston, \& Gelernter, 1989; Pelham et al., 1997). Most of this research suggests experimentally manipulated negative affect increases drinking. Based on identification of unresolved questions, the current experiment manipulates a specific type of negative affect. We now turn to studies that more precisely highlight these issues.

Anxiety manipulations. A small body of research has examined the effect of manipulated anxiety on subsequent alcohol use in the laboratory. These studies can be classified in two ways. Some measure alcohol consumption after the completion of a stressor, while others measure alcohol consumption when a participant is expecting a stressor.

Post-Stress Alcohol Use. In two studies, participants either casually talked to an experimenter or completed a modified Trier Social Stress Task, which involves doing mental arithmetic in front of judge(s) (de Wit, Soderpalm, Nikolayev, \& Young, 2003; Gordh, Brkic, \& Soderpalm, 2011). Subsequently, participants could freely consume up to six alcoholic beverages for 30 minutes. De Wit and colleagues found that those in the stress condition drank more than participants in the control condition, although only people with a family history of alcoholism showed such an increase in the Gordh et al (2011) study.

The anxiety manipulation described above (de Wit et al., 2003; Gordh et al, 2011) is similar to one used in another study (Thomas, Bacon, Randal, Brady, \& See, 2011). Thomas and colleagues had 79 non-treatment seeking alcohol dependent adults complete a five-minute version of the arithmetic procedure in addition to a public 
speaking task. These procedures were completed in front of stoic judges, whom participants were told had expertise in interpreting body language and behavior. Afterwards, participants were given a set dose of alcohol to prime drinking, followed by a 15 -minute bogus beer taste test. Approximately twice as many people in the stress condition, versus those in the control group, drank all beer provided. Although in the expected direction, there was no significant effect on volume of beer consumed, $d \approx 0.20$. The authors attribute this to a possible ceiling effect, since many participants drank the entire 24 ounces.

It should be noted, however, that the evidence manipulated anxiety increases consumption was modest in two other studies (Larsen, Engels, Granic, \& Huizink, 2013; Nesic \& Duka, 2006). Nesic and Duka had heavy social drinkers read an art book or deliver a five-minute speech, which would supposedly be judged for nonverbal behavior. When participants were allowed to freely consume alcohol for 15 minutes after this procedure, the stressor did not appear to effect alcohol consumption ${ }^{2}$.

Larsen and colleagues (2013) used a highly ecologically valid ad-lib drinking scenario. One hundred six adult men took part in an ostensible study on mood. Participants either completed puzzles or gave a three-minute speech on why they should be chosen for a fictitious job. Next, they were invited to relax in a "bar lab," which mimicked a real-world pub (described in further depth below) with a heavy or light-drinking confederate. Counter to expectations, there was no main effect of anxiety on consumption. The authors suggest the null findings could be a result of the

\footnotetext{
${ }^{2}$ This was not explicitly reported in the paper, but is inferred by a visual examination of Figure 3 collapsing across genders.
} 
strong modeling effect. Participants with a heavy drinking confederate consumed about three times the amount as those with a light drinking confederate, potentially overriding the more subtle influence of stress on alcohol consumption.

Consumption during anticipatory anxiety. It is crucial to consider the effect of an anxiety manipulation on drinking behavior when the participant is anticipating, instead of reacting to, a stressful event. In our view, anticipatory drinking is highly consistent with real world alcohol use. Research on college students has shown that pre-gaming, which is characterized by consuming alcohol prior to a party or event, is often done to alleviate stress during impending social interactions (Pedersen, LaBrie, \& Kilmer, 2009). In addition to being more ecologically valid, we view anticipatory anxiety as an especially potent manipulation. Specifically, people may be more likely to engage in behaviors that they believe reduce stress (such as drinking) when expecting a stressful event in the near future. To our knowledge, six experiments have measured ad lib alcohol use in experimentally induced anticipatory-anxiety states (Abrams Kushner, Medina, \& Voight, 2002; Corcoran \& Parker, 1991; Higgins \& Marlatt, 1975; Kidorf \& Lang, 1999; McNair, 1996; Tucker, Vuchinich, Sobell, \& Maisto, 1980).

Higgins and Marlatt (1975) randomly assigned 64 male heavy drinking students to a social anxiety or control condition. Those in the social anxiety group were told that after a taste-test (described below), they would take part in another study that required them to discuss interpersonal attractiveness with a group of women. They were further informed that the women would rate them on a number of "desirable" characteristics. Participants in the control condition were told they would 
rate pictures of women on attractiveness. After this procedure, all participants did a wine taste-test which involved rating multiple wines on 63 dimensions. They were allowed to drink as much as necessary to make their ratings (Higgins \& Marlatt). Participants in the anxiety condition drank significantly more during the taste-test than those in the control condition $d \approx 0.79$.

Kidorf and Lang (1999) examined anticipatory anxiety effects on alcohol use among 84 male and female students in a within-subjects design. In the first session, participants were individually brought into a laboratory and told by an experimenter that they were studying the effect of alcohol on "self reported psychological and physiological responding” (p. 137). Participants were allowed to drink alcohol ad lib in a relaxing setting while answering questions on their mood. This procedure was replicated in the second session with one key difference. Alcohol was consumed after participants were told they would have to give a 15-minute speech on their most undesirable characteristic. To enhance the manipulation, participants were also informed the speech would be recorded and evaluated by faculty and students. As hypothesized, significantly more alcohol was consumed in the second session compared to the first session $d=0.16$.

In another study, 40 heavy drinking males who allegedly signed up for an experiment on the relation between beverage taste ratings and a visual task were assigned to a high or low stress condition (Tucker et al., 1980). Those in the highstress group were led to believe they would have to complete a difficult visual task that was allegedly indicative of abstract reasoning ability. Participants in the lowstress group were led to believe the task was easy, and told it would not be graded or 
timed. Afterwards, participants completed a taste-test similar to the one used by Higgins and Marlatt (1975). Participants in the high-stress group drank considerably more wine than those in the low-stress group, $d=2.1$.

In contrast to these positive findings, three other studies observed no effects of anticipatory anxiety on subsequent drinking. McNair (1996) had 60 moderate or heavy drinking college women complete a taste test under anticipatory or post-stress anxiety for a study that supposedly examined scales designed to test "(1) speech patterns, (2) the taste characteristics of two types of wine, and (3) the interest level of a reading passage.” (p. 336). Of note, she also manipulated anxiety valence. Participants in the high-stress condition were asked to give a videotaped two-minute self-disclosing speech, while those in the low-stress condition were videotaped while reading. Contrary to expectations, there were no significant main effects or interactions. However, with only 60 participants total, and 30 in the anticipatory anxiety arm, this study was highly underpowered for a $2 \times 2$ between-subjects design. This limitation is especially problematic since high anxiety was being compared to low anxiety instead of a non-stress control, further reducing the expected effect size. Corcoran and Parker (1991) told 69 undergraduates they would either be evaluated on a written essay, or that they would give a 10-minute presentation on their most embarrassing body part. During a 20-minute preparation time, participants were offered alcoholic or non-alcohol drinks as refreshments. There was no difference in the quantity of alcohol consumed between conditions. However, close to half of all participants chose not to drink any alcohol, so there may have been a floor effect. 
Abrams and colleagues (2002) had social drinking adults with social phobia read quietly or give a two-minute speech in front of others. Half the participants were offered drinks designated as "weak", "moderate", or "strong" in alcohol at five times eight minutes apart prior to the completion of the reading task or speech. Those in the anxiety condition chose drinks of comparable strength to participants in the control group $^{3}$. With only 20 participants, however, most effects would go undetected.

Neuroticism and alcohol use. Rather than manipulating affect, several studies have analyzed relations between laboratory consumption and broadband traits reflecting tendencies toward negative affect, such as neuroticism. As detailed above, in contrast to the consistent positive associations observed between neuroticism and alcohol use/problems in survey research, laboratory studies have not observed significant associations (Leeman, Corbin, \& Fromme, 2009; Peterson, Morey, \& Higgins, 2005; van Schoor, Bot, \& Engels, 2008). Leeman and colleagues had participants complete the revised Eysenck Personality Questionnaire, and were subsequently allowed to drink alcohol while preparing to give a self-disclosing speech. Neuroticism was not associated with alcohol consumption in response to the social stressor. This study is consistent with previous work (Higgins \& Marlatt, 1973), which found that the neuroticism dimension of the Eyesenck scale did not correlate with ad lib laboratory alcohol consumption in 40 male alcoholics and social drinkers.

More recent studies have also found null results when using a Big Five measure of neuroticism, instead of Eysenck's scale (Peterson et al., 2005; van Schoor, et al., 2008). Specifically, in an experiment by Peterson and colleagues, laboratory

\footnotetext{
${ }^{3}$ The authors report a trend for increased consumption in the control, versus anxiety, condition. However, the difference appears to be statistically non-significant
} 
consumption was unrelated to any personality subscale among a sample of 30 male social drinkers doing a taste test in random dyads. Although a subsequent experiment (van Schoor et al) used a more realistic drinking paradigm (ad lib drinking among intact friend groups in a bar laboratory), this study also did not observe significant relations between personality and alcohol consumption. As noted, these results are inconsistent with the survey research, described earlier (Littlefield et al., 2009, 2010; Malouff et al., 2007). This difference can likely be attributed to limited sample sizes and the fact lab studies observe alcohol use in a short-time period, whereas survey research examines self-reported alcohol consumption over longer time intervals and also assesses alcohol consequences and alcohol use disorders (Littlefield et al., 2009, 2010; Malouff et al). Nonetheless, the discrepancy is still curious because one would not expect neuroticism to selectively influence certain components of alcohol involvement, but not others.

\section{Laboratory studies on interactions between state and trait anxiety. To}

date, we have identified four experiments that examined the interaction between personality and manipulated affect on alcohol consumption in the laboratory. Two studies have looked at this effect under post-stress consumption, by giving positive or negative feedback to male participants on their social ability (Holroyd, 1978) or intelligence (Hull \& Young, 1983). For those receiving positive feedback, trait anxiety (Hull \& Young) and social anxiety (Holroyd) were unrelated to ad lib alcohol use. However, among participants who received negative feedback, both general and social anxiety demonstrated significant positive associations with ad lib drinking. 
Two other experiments, also discussed earlier, analyzed the interaction between trait anxiety and state anticipatory social anxiety. Kidorf and Lang (1999) had participants consume alcohol during a stress-free period and while anticipating a self-disclosing speech. More alcohol was consumed in the anxiety versus control condition, especially for participants high in trait social anxiety. Higgins and Marlatt (1975) had participants do a taste test after being told they would either participate in a socially stressful, or non-stressful, second experiment. For those in the control condition, there was no association between neuroticism and alcohol consumption. However, there was a marginal positive correlation between neuroticism and alcohol use among participants receiving the social anxiety induction. In sum, all four studies (Higgins \& Marlatt; Holroyd, 1978; Hull \& Young, 1983; Kidorf \& Lang) provide preliminary evidence of an interaction effect, such that a state-anxiety manipulation may be especially likely to increase consumption among people with high pre-existing levels of anxiety.

\section{Unresolved Issues}

There is a wealth of survey research on the relation between anxiety, neuroticism, and alcohol use and misuse. However, laboratory studies in this area are lacking and inconsistent with respect to the role of social anxiety on alcohol use. As reviewed above, there is also some evidence to suggest an interaction effect between state and trait anxiety, such that individuals who are high on trait anxiety drink more in response to anticipatory social anxiety manipulations than those who are lower on trait anxiety. The current study sought to replicate and extend this small body of literature, as well as address several methodological issues detailed next. 
Methodological issues should be considered in relation to the six most relevant studies that manipulate anticipatory social anxiety and measure $a d$ lib alcohol use (Abrams et al., 2002; Corcoran \& Parker, 1991; Higgins \& Marlatt, 1975; Kidorf \& Lang, 1999; McNair, 1996; Tucker, et al., 1980). Most notably, none of these experiments had participants drink in an ecologically valid context. Other than Abrams et al., participants always drank alone even though alcohol is typically consumed in social settings (Gronkjaer, Vinther-Larsen, Curtis, Gronbaek, \& Norgaard, 2010). While having participants drink in groups raises other issues, it more closely approximates real world drinking. Although widely used in early laboratory research, the "taste test paradigm" used in many of these studies (Higgins $\&$ Marlatt, McNair, Tucker et al) also does not reflect alcohol consumption in a realworld setting, where drinking much less rigid. Moreover, Kidorf and Lang used a within-subject design with participants always receiving the anxiety induction in the second session. The authors recognized this limitation, and suggest that more alcohol may have been consumed in the stress condition simply because participants felt more comfortable drinking. Finally, the rationale for consuming alcohol was often poorly specified.

Administering or providing access to alcohol introduces a number of potential logistical and human subject issues, most notably with respect to the U.S. minimum legal drinking age of 21. It is time, labor, and resource intensive in that participants must remain in the laboratory until their blood alcohol levels reach near zero levels necessitating participation incentives. As noted, placebo alcohol has often been used as an independent variable in studies assessing the pharmacological effect of alcohol 
on a particular outcome (e.g., aggression). However, it is rarely assessed as a dependent variable, or used with underage participants. Given the practical issues associated with real alcohol, the current experiment examines the viability of this approach with placebo alcohol.

\section{Current Study}

The current study sought to replicate and extend past research analyzing the relation between laboratory alcohol consumption and trait and state social anxiety. We also addressed the methodological limitations detailed above and investigated the utility of a new approach that could facilitate future laboratory studies of alcohol consumption. Consistent with recent research (Bot et al., 2007; Larsen et al., 2010; 2012; 2013) our methodology, utilizing a bar-laboratory setting, is designed to more closely approximate real world drinking while maintaining sufficient experimental control. It corresponds with the reality that drinking often takes place during down time (i.e. Bot et al., 2007), and the fact that people have the option of refusing drinks (Larsen et al, 2010, 2012). Only one study, (Larsen et al., 2013), reviewed earlier, has utilized this methodology when manipulating anxiety, but did so in a small sample of men only during post-stress alcohol consumption.

Based on our literature review, we forward two primary hypotheses. First, we expected that participants who anticipate giving a self-disclosing speech would drink more placebo alcohol than participants in a control group. Second, an interaction between state and trait social anxiety was hypothesized. Specifically, we predicted that the effect of state anticipatory social anxiety on alcohol use would be especially 
strong for participants with elevated trait social anxiety. Ancillary analyses examined whether neuroticism moderated state anxiety - placebo alcohol relations. 


\section{METHOD}

\section{Participants and Recruitment}

Participants were recruited from 100- and 200- level psychology classes ${ }^{4}$ in exchange for class credit at a medium-sized New England university. Class announcements were made for a study examining the effects of alcohol on language fluency. Interested students were instructed to email the research staff and were subsequently contacted by phone or through email to query eligibility and arrange a study session if eligible. Participants were ineligible if they were: under 18 years old $(n=1)$, did not consume alcohol in the past three months $(n=10)$, thought they might be pregnant $(n=1)$, or ever attended Alcoholics Anonymous meetings or alcohol/drug use treatment $(n=1)$. Of the 164 who participated, 28 participants were excluded because they terminated the study early $(n=2)$, had prior knowledge of the experiment $(n=9)$, were skeptical about our cover story in a manner that compromises their data $(n=1)$, did not believe they were drinking real alcohol $(n=14)$, or participated in a study session where all other participants were excluded for one of the reasons listed above $(n=2)$.

Thus, the sample used to examine the effect of social anxiety on alcohol consumption is comprised of $N=136$ participants in $k=54$ groups who ranged from 18 to 28 years old $(M=18.80, S D=1.26)$. Most participants were female $(61 \%)$, and White (83.8\%). Other races included: Black or African American (2.3\%), Asian (3.8\%), multi-racial (4.6\%), and other (5.4\%). The University of Rhode Island IRB approved all policies and procedures.

\footnotetext{
${ }^{4}$ One participant was also recruited from a 100-level gender studies class
} 


\section{Materials}

Demographics. Participants were asked to indicate their age, gender, and race, although we did not assess ethnicity (Hispanic/Latino).

Daily alcohol drinking questionnaire (DDQ). This measure asks participants to record the typical number of standard drinks on each day of the week within the past three months (Collins, Park, \& Marlatt, 1985). Standard definitions of a drink as equal to $12 \mathrm{oz}$. of beer, $5 \mathrm{oz}$. of wine, and $1.5 \mathrm{oz}$. of liquor were provided to participants. From this measure, we computed average number of drinks per week.

Heavy Episodic Drinking (HED). HED was assessed by asking "How many times have you had five or more drinks in a row during the past two weeks?"

Brief Young Adult Alcohol Consequences Questionnaire (B-YAACQ). The B-YAACQ (Kahler, Strong, \& Read, 2005) is a 24-item psychometrically validated measure, derived from the Young Adult Alcohol Consequences Questionnaire (YAACQ). Using a dichotomous (yes/no) response option, participants indicated whether they experienced a variety of alcohol-related consequences within the past year (e.g. "I have passed out from drinking"). The questionnaire was scored by taking the total number of consequences endorsed ( 0 to 24$)$. Coefficient alpha was .779 in the current study.

\section{Social Interaction Anxiety (SIAS-6) and Social Phobia Scale (SPS-6).}

Short forms of the SIAS and SPS were given (Peters, Saunderland, Andrews, Rapee, \& Mattick, 2012) as measure of trait anxiety. Each scale consists of six items on a " 0 " (Not at all characteristic or true of me) to " 4 " (Extremely characteristic or true of me) Likert scale (e.g. for SIAS, "I have difficulty talking with other people"; for SPS, 
"I worry I might do something to attract the attention of other people"), and scores were calculated by taking the mean (with potential values ranging from 0 to 4 ). These measures are psychometrically validated, and highly correlated with the full scales from which they were derived (Mattick \& Clarke, 1998). Coefficient alpha was .849 in our sample.

\section{Spielberger State-Trait Anxiety Inventory (STAI) Short Form. This} consists of six items from the 20-question STAI state form (Marteau \& Bekker, 1992; Spielberger et al., 1983), as a measure of state anxiety only. The state STAI survey is a commonly used measure of anxiety, and is correlated with the short form at $r=.95$ (Marteau \& Bekker). The survey is scored by taking the sum of responses to six items on a 4-point Likert scale from 1 (not at all) to 6 (extremely). As such, values could range from 6 to 24 . We observed a coefficient alpha of .767 .

Neuroticism. Participants completed the neuroticism subscale of the Big Five Inventory (BFI) created by John, Donahue, and Kentle (1991). It consists of eight questions that ask participants the extent to which a series of phrases (e.g., get nervous easily) applies to them on a scale from 1 (disagree strongly) to 5 (agree strongly). This survey is scored by taking the mean value across all items. The BFI subscales have good reliability and validity (Rammstedt \& John, 2007). Coefficient alpha was .763

Movie rating. To support the veracity of a task designed to distract participants (described in the procedure), they were asked to rate a movie segment from 1 (not at all) to 5 (extremely) on the following dimensions: a) Interesting, b) 
Engaging, c) Funny, and d) Realistic. They were also asked to complete one openended question: "What was the best and worst part of the clip?"

Alcohol believability. To help determine whether the placebo deception was effective, participants were asked the following questions: 1) "How many alcoholic drinks did you have?"; 2) "How many non-alcoholic drinks did you have?"; 3) "Please estimate your level of intoxication" from 1 (I did not feel the effects of alcohol whatsoever) to 5 (The alcohol made me drunk); 4) "Please estimate your current Blood Alcohol Content (BAC)," with possible responses ranging from .00 to .10 in increments of .01, and an anchor of "intoxicated" at .08.

\section{Procedure}

All participants were scheduled in same-sex groups of 2-3 between 4:15 and 8:35 pm Sunday - Wednesday. These times were chosen so that participants were unlikely to have classes or commitments later in the day which would prevent them from drinking. We also did not run sessions during typical drinking nights (Thursday - Saturday) out of concern that some students may use this study as a pre-game. Sessions were not run if only one participant arrived, since our analytic procedures (as discussed below), are predicated on group alcohol consumption. To enhance the credibility of the placebo deception, prior to arriving, participants were told they should: refrain from alcohol for 12 hours before their session, avoid eating a large meal earlier in the day, verify that it is safe to consume alcohol with any medications they might be taking, and to immediately cancel if they thought they might be pregnant prior to their scheduled time. Prior to running the procedure discussed here, a pilot test with 18 participants yielded a lower than optimal (under 75\%) rate of 
placebo alcohol deception. Accordingly, we modified our procedures to incorporate a confederate, interacting as described below, as well as floating a small amount of alcohol and rum extract on top of drinks.

Upon arriving to the laboratory, participants were joined by a same-sex confederate $^{5}$. After being greeted by a female experimenter, each person was brought into a small, isolated room. Here, participants completed a consent document, received a breathalyzer test to verify abstinence (nobody registered as having a positive $\mathrm{BrAC}$ ), and were asked to verbally confirm they were not taking medication, nor did they have a medical condition, that would contraindicate alcohol. Next, participants completed a series of questionnaires (demographics, DDQ, B-YAACQ, SIAS-6, SPS-6, neuroticism) and were administered the social anxiety or control protocol. Random assignment to conditions occurred at the group level, although each person was given these instructions while isolated.

Based on a procedure used by Sher and colleagues (Sher, Bylund, Walitzer, Hartmann, \& Ray-Prenger, 1994), participants in the social anxiety condition were told that after the next portion of the study, to assess language fluency in real world situations:

A man/woman (opposite sex) will enter a room with you and the other participants. You are to speak to him/her about how you would impress someone on a date. You should make as favorable an impression as possible, such that he/she, as well as the other participants, will think you are fun and engaging on dates. He/she is instructed not to talk back. It is important that the speech last five minutes. It will be video-recorded and used for training clinical psychology students. Afterwards, you will be

5

For $n=9$ participants over $k=3$ groups, no confederate was present. Since all of these participants believed they were drinking alcohol, we elected not to exclude them. 
asked a few questions about how difficult the task was. You can take a moment to prepare and gather your thoughts and I'll be back in a minute.

These instructions were given slowly and with eye contact. Participants were also provided with scrap paper that they could use to brainstorm their speech. Those in the control group were told:

For the fluency procedure, which will happen after the alcohol portion of the study, you will return here and read a poem. Afterwards, you will be asked a few questions about how difficult the task was.

After receiving their instructions, participants were left alone for approximately one minute to encourage rumination. When the experimenter returned, she asked participants to complete the STAI short form as an anxiety manipulation check. Next, group members assembled in a common area and were escorted to a barlab. While walking, the confederate said "I'm excited - my friend did this study last week and came back to [name of freshmen/sophomore residence hall] pretty buzzed."

Upon arriving at the bar-lab, the experimenter introduced participants to a female bartender (Study RA) who was naive to study condition. Consistent with other research (e.g. Bot, Engels, \& Knibbe, 2005), the bar-lab was designed to mimic a realworld bar. As such, popular music was played, snacks were provided, and the room was furnished with a bar and bar décor. The experimenter explained that "this is the alcohol portion of the study," and participants could consume non-alcoholic or alcoholic beverages prior to the fluency procedure. The bartender presented everyone with a menu, but, as done by Bot et al. (2005), said "you must personally ask for all beverages, since it would be unethical for us to ask participants directly." This was done to keep interactions between the bartender and study participants constant across sessions. 
All "alcoholic drinks" were soda or juice mixed with "liquor" (in reality flattened tonic water) in a 5:1 ratio. To increase the perception of alcohol, we poured the tonic water from real liquor bottles and floated $1 \mathrm{~mL}$ each of rum extract and tequila on top of every drink. Additionally, we used to tequila to rim glasses and spray the room prior to each session. We also soaked lemons in tequila and added them to each "alcoholic" beverage. Throughout the 20-minute drinking period, the bartender unobtrusively recorded the type and quantity of every beverage consumed for each participant. ${ }^{6}$

Upon receiving the menu, the confederate ordered an alcoholic drink, took a sip, looked disgusted, and said, "I hate the taste of [name of liquor]." Shortly afterwards, he/she got the bartender's attention and said “Sorry, I forgot I didn't like [liquor in initial drink]. Would it be OK to get a [new drink] instead?" The confederate consumed this beverage in 10 minutes. Next, he/she ordered another drink, and after a few sips, said: "I'm definitely feeling this - good to be a lightweight sometimes!" The confederate consumed half of this drink. All sips were paced evenly.

At the beginning of the drinking portion, to avoid having participants in the anxiety condition discuss stress-reducing strategies for their impending speech, the experimenter mentioned that materials were being developed for a different study, and they were asked to watch a movie clip and answer a few questions. Next, the experimenter handed out the movie rating sheet and played the first 17-minutes of Happy Gilmore, which does not contain any reference to alcohol. Three extra minutes,

\footnotetext{
${ }^{6}$ All drinks held exactly 9 ounces, and the quantity of any remaining liquid was measured for all beverages that a participant did not finish.
} 
during which participants could still drink, were provided to complete the movie rating form. All beverages were collected after the 20-minute drinking period. Finally, participants were asked to complete the alcohol believability questionnaire and were escorted back to their original, isolated room for the debrief.

\section{Debriefing.}

Each participant was administered a lengthy funnel debrief ${ }^{7}$ adapted from Wood (1996). Each participant's responses were carefully analyzed to determine whether he/she believed the experiment involved real alcohol. The debrief included questions such as "How strong do you think these drinks were compared to what you usually consume?" and "Is the effect [you reported on the alcohol believability questionnaire] what you would normally experience while drinking that amount?" Typically, these questions served as a starting point for a larger discussion surrounding their perception of alcohol during the study. The experimenter would continue to ask scripted or non-scripted questions until a subjective evaluation of the degree of believability on a 5-point Likert Scale could be obtained. Any participant with a rating of 3 ("Moderate suspicion the alcohol was weaker than usual") or lower was considered deceived, and participants with a rating higher than 3 were considered not deceived. For all borderline cases, the experimenter carefully documented the participant's responses and discussed these with the junior author (MHB). As necessary, the junior and senior author (MDW) also discussed borderline decisions on a case-by-case basis.

\footnotetext{
${ }^{7}$ All experimenters were trained on performing a debrief by the junior author, who initially helped with these on all study sessions. No experimenter did a debrief alone until the junior author believed she was adequately trained.
} 
After querying the participant for the extent to which he/she believed real alcohol was being consumed, the experimenter said "We told you that this experiment examined the effect of alcohol on verbal fluency. While doing the study, did you ever think we were interested in something else?" If the participant said yes, the experimenter probed for what he/she believed we were interested in, when he/she first had that thought, and how strong of a suspicion he/she had. At the end of the debrief, the experimenter asked "Did you know anything about this study prior to arriving, other than what we've told you?" If the participant indicated he/she did have prior knowledge, the experimenter probed for what the participant knew. Finally, we explained the true aim of the study, informed participants they received a placebo, and said they would not be asked to complete the fluency procedure. Before leaving, participants were asked to sign an affidavit saying they would not discuss the study for at least one year, as well as indicate their confidence in being able to keep the terms of the affidavit on a 4-point Likert scale from 1 (not at all confident) to 4 (extremely confident). 


\section{RESULTS}

\section{Preliminary Analyses}

We examined the assumptions underlying our analytic approaches, conducted a principal components analysis on our social anxiety measures and conducted exploratory analyses. Since data are analyzed with a Multi-Level Model (MLM) (see below), we checked for normality, linearity, and homoscedasticity on the outcome (laboratory alcohol use), as violations of these assumptions can result in bias estimates (Maas \& Hox, 2004). Alcohol consumption was normality distributed (skewness $=0.29$, kurtosis $=0.98$ ), and visual inspection of a scatter-plot verified linearity. Results from a Levine's test demonstrated that variance was comparable in the stress and control condition, $F(2,134)=<1.0$, suggesting homoscedasticity.

Using software provided by Patil, Singh, Mishra, and Donavan (2007), we conducted a Parallel Analysis (Horn, 1965) with the SIAS and SPS items. A onefactor solution best fit the data, so Social Anxiety was calculated as a mean of all 12 items across both 6-item questionnaires.

See Table 1 for descriptive statistics and bivariate correlations between study variables. Of note, participants were moderately heavy drinkers who consumed an average of $11.00(S D=7.91)$ drinks per week, and had $15.41(S D=6.21)$ ounces of "alcoholic" beverages (which is equivalent to 1.71 9-ounce glasses) during the 20minute drinking period. Drinks per week and HED were positively related to lab alcohol consumption ( $r \mathrm{~s}=.199$ and .213 , respectively). Although neuroticism was inversely associated with self-report drinking (for drinks per week, $r=-.232$; for HED, 
$r=-.196)$, it was unrelated to alcohol consumption in the bar-lab. Social Anxiety was uncorrelated with both self-report and observed drinking.

Next, a series of $t$-tests were conducted comparing men and women on drinks per week, HED, and alcohol related consequences. Men $(M=12.44, S D=8.62)$ scored higher than women $(M=9.42, S D=7.03)$, on drinks per week, $t(133)=2.97, p<.01$. There was a trend for men $(M=1.96, S D=1.63)$ to also report greater frequencies of HED than women $(M=1.42, S D=1.56), t(134)=1.94, p=.055$. No differences between men $(M=7.73, S D=3.58)$ and women $(M=6.72, S D=3.86)$ were observed for alcoholrelated consequences, $t(134)<1.0$.

\section{Manipulation Checks}

As discussed above, we probed for prior knowledge, cover story believability, and awareness of study deception during the funnel debrief. Nine participants indicated they had prior knowledge to sensitive aspects of the study from a friend or acquaintance that already completed the experiment. Additionally, one participant was highly skeptical of our cover story.

Fourteen participants did not believe they were drinking real alcohol, according to the believability rating made by the experimenter (and conversations with the junior and senior author, as necessary). We compared the "non-deceived" participants with "deceived" participants on a variety of self-report measures to determine the accuracy of our classification. All of these comparisons entail the $n=14$ (9.5\%) non-deceived participants and $n=133(90.5 \%)$ deceived participants. The latter group represents participants who were not excluded for any reason delineated above ( $n=136)$ and chose to consume at least some amount of "alcohol" ( $n=3$ did not). The 
average believability rating for deceived and non-deceived participants was 1.41 $(S D=.643)$ and $4.43(S D=.616)$, respectively. Among non-deceived participants, $92.9 \%$ estimated their BAC at .00 , while only $3.8 \%$ of deceived participants did so (deceived participants rated their BAC at an average of .025[SD=.015]). Additionally, according to the junior author's content coding of responses to the question "Is the effect [you reported on the alcohol believability questionnaire] what you would normally experience while drinking that amount," $36.4 \%$ of non-deceived participants and $90.6 \%$ of deceived participants indicated their level of intoxication was at least equal to drinking that amount of alcohol outside the laboratory. Among non-deceived participants, $85.7 \%$ indicated that they "did not feel the effects of alcohol whatsoever," whereas only $34.6 \%$ of deceived participants reported this.

Of note, all of these participants, regardless of classification with respect to alcohol deception, indicated that they consumed at least some portion of an alcoholic beverage in response to the question "How many alcoholic drinks did you have?" Furthermore, a disproportionate number of non-deceived participants completed the study in later sessions $(57.1 \%$ were among the final $23.3 \%$ of participants to take the study), which suggests that some may have actually had prior knowledge from classmates telling them about the experiment, but were reluctant to share that information with us. Thus, it is possible they were erroneously classified as "nondeceived," rather than "prior knowledge."

Regarding our social anxiety manipulation, we conducted a t-test comparing STAI results between study conditions. Participants in the anxiety condition scored 
significantly higher on the $(M=12.38, S D=2.76)$ than participants in the control condition $(M=9.51, S D=2.79), t(133)=6.00, p<.001$, Cohen's $d=1.04$.

To verify that participants in the anxiety group were similar to those in the control group, we ran $t$-tests comparing participants on age, trait anxiety, neuroticism, drinks per week, heavy episodic drinking, and alcohol consequences across conditions. None of these differences were significant (all $p \mathrm{~s}<.1$ ), which suggests that random assignment was successful in creating comparable groups (Table 2).

\section{Laboratory Alcohol Use And Negative Affect}

Next, we tested our primary hypotheses that: a) Participants in the stress group would drink more alcohol than those in the control group; and b) there would be a state social anxiety by trait social anxiety interaction, such that trait socially anxious participants would be especially likely to drink more after elevated state anxiety. These hypotheses were tested using a Multi-Level Model (MLM). An MLM is necessary because participants are nested within groups, so the assumption of independence is violated, especially since there is a strong modeling effect of alcohol consumption (Quigley \& Collins, 1999). This model was run using the PROC MIXED command in SAS version 9.2 (see Singer, 1998). State social anxiety (1=did not receive stress-induction, $2=$ did receive stress induction), trait social anxiety, and a state anxiety by trait social anxiety interaction score were entered as level one predictors. The participant's group, used as a level two predictor, was entered as a categorical variable. The dependent variable was laboratory alcohol consumption. The intra-class correlation (ICC) in this model was .42, which suggests that $42 \%$ of the variance in laboratory alcohol use can be attributed to a group effect. State social 
$\operatorname{anxiety}^{8}(\beta=-70.16, t=-1.40)$, trait social anxiety $(\beta=-11.98, t=-.14)$, and the state by trait anxiety interaction $(\beta=30.58, t=0.54)$ were all unrelated to alcohol use, $p \mathrm{~s}>.15$.

Ancillary analyses were performed to test whether neuroticism moderates the relation between state anxiety and alcohol consumption. As such, we performed another MLM with state anxiety (1=did not receive stress-induction, $2=$ did receive stress induction), neuroticism, and a state anxiety by neuroticism interaction as level 1 predictors, the participant's group as a level 2 predictor, and alcohol consumption as the dependent variable. Neuroticism $(\beta=105.56, t=1.24)$, and more crucially, the state anxiety by neuroticism interaction $(\beta=-86.36, t=-1.59)$, were also unrelated to alcohol use, $p \mathrm{~s}>.1$.

Participants in the control consumed an average of $16.42(S D=6.36)$ ounces, while those in the anxiety group drank an average of $14.27(S D=5.88)$ ounces. 
Table 1

Bivariate Correlations

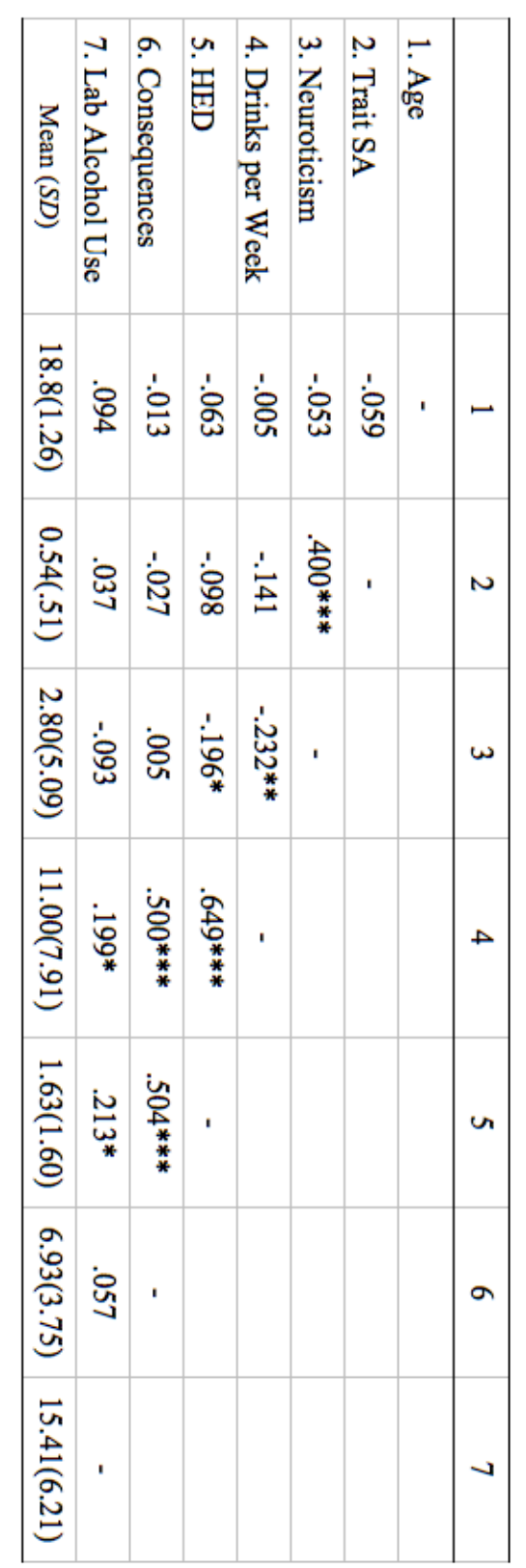

Note: Bivariate correlations between study variables are shown above. SA=Social Anxiety, HED=Heavy Episodic Drinking. Trait SA was assessed with the SIAS and SPS short forms, and Neuroticisms was measured with Big Five questionnaire. HED refers to the past 2 week frequency of 5 or more drinks, and alcohol consequences was assessed with the Brief Young Adult Alcohol Consequences Questionnaire. 
Table 2

Comparison of Participant Characteristics Across Conditions

\begin{tabular}{lllllll}
\hline \multirow{2}{*}{ Variable } & \multicolumn{2}{c}{ Anxiety } & \multicolumn{2}{c}{ Control } & & \\
\cline { 2 - 5 } & $M$ & $S D$ & $M$ & $S D$ & $t(p<.01)$ & $d f$ \\
\hline Age & 18.80 & 1.13 & 18.79 & 1.38 & -0.01 & 125 \\
Trait SA & 0.51 & 0.51 & 0.56 & 0.52 & 0.53 & 134 \\
Neuroticism & 2.76 & 0.52 & 2.85 & 0.50 & 1.09 & 134 \\
Drinks per Week & 12.17 & 7.95 & 10.00 & 7.79 & -1.60 & 133 \\
HED & 1.70 & 1.74 & 1.58 & 1.48 & -0.45 & 134 \\
Alcohol Consequences & 7.37 & 3.98 & 6.56 & 3.53 & -1.25 & 134 \\
\hline
\end{tabular}

Note: Participants in the anxiety and control group were similar on all variables tested. SA=Social Anxiety, HED=Heavy Episodic Drinking. Trait SA was assessed with the SIAS and SPS short forms, and Neuroticisms was measured with Big Five questionnaire. HED refers to the past 2 week frequency of 5 or more drinks, and alcohol consequences was assessed with the Brief Young Adult Alcohol Consequences Questionnaire. 


\section{DISCUSSION}

The main purpose of this study was to investigate the role of state and trait social anxiety on ad lib placebo alcohol use in a naturalistic setting. We hypothesized that an anticipatory state social anxiety manipulation would increase alcohol use in a bar-laboratory among same-sex groups, particularly for those with elevated trait social anxiety. However, neither the hypothesized main effect nor interaction was observed, despite careful manipulation checks to ensure the social anxiety manipulation increased stress, and that participants believed they were consuming real alcohol.

Past research examining the role of anticipatory anxiety on alcohol use has yielded mixed results, with some studies observing elevated consumption among participants expecting a stressful event (Higgins \& Marlatt, 1975; Kidorf \& Lang, 1999; Tucker et al., 2000), and others finding no difference (Abrams et al., 2002; Corcoran \& Parker, 1991; McNair, 1996). Initially, we considered that methodological factors were the most likely explanation for the non-significant findings. Namely, statistical power was limited in the Abrams et al and McNair study, which only enrolled 20 and 30 participants, respectively ${ }^{9}$. However, as discussed below, the null results in this study suggest that the non-significant findings could be a result of the social anxiety induction that was used here and in prior research.

In the current study, participants assigned to the stressor expected to give a videotaped five-minute speech in front of their group members to a silent opposite sex experimenter about how to impress someone on a date. While these participants scored one standard deviation higher on a survey measure of anxiety, it only raised

\footnotetext{
${ }^{9}$ Excluding participants in the post-stress conditions
} 
scores to average of 12.38 out of a possible 24 , which may not be high enough to encourage anxiety-reducing behavior. Furthermore, although the task was geared towards elevating social anxiety, it may have promoted performance anxiety as well. Safren and colleagues (1999) observed different factors for anxiety related to social interaction (i.e. "meeting strangers") and public speaking (i.e. "acting, performing, or giving a talk in front of an audience"), so these two types of anxiety may be qualitatively distinct. Thus, a "pure" social stressor would simply cause participants to be stressed about an interpersonal interaction, rather than worry about delivering a speech.

A large body of research suggests that drinking to cope with stress is a common motivation for alcohol consumption (e.g. Cooper, 1994; Park \& Levenson, 2002). Although less work has been done on motivation for drinking with regard to social anxiety specifically, there is high comorbidity between Alcohol Use Disorder and Social Anxiety Disorder (Buckner \& Turner, 2009) and Social Phobia (Kessler et al., 1994). In addition, one survey study found that people with high social anxiety were almost twice as likely to report drinking to cope with an impending social situation, and derived greater anxiolytic benefit from alcohol in compared to nonanxious controls (Thomas, Randall, \& Carrigan, 2003).

Even if people drink to cope with social anxiety (or stress more generally), performance anxiety could operate to reduce drinking because of concerns about performance decrements while intoxicated. Of note, the three other studies observing no effect of anticipatory anxiety on alcohol use also manipulated anxiety by telling participants they would be delivering a speech (Abrams et al., 2002; Corcoran \& 
Parker, 1991; McNair, 1996). In a review of laboratory studies on social anxiety and alcohol use, Battista, Stewart, and Ham (2010) argue that interaction-, rather than performance-based, social anxiety manipulations "may be more representative of the types of situations that would motivate socially anxious individuals to drink alcohol." (p. 16). However, any task that forces participants to give a speech in front of other people is still social in nature, so this explanation is speculative. Further research is needed to disentangle the extent to which social and performance anxiety are distinct constructs, and whether they have different effects on alcohol use.

\section{Methodological advantages and implications}

The current study provides methodological insight into laboratory studies of alcohol use. Namely, we designed a new procedure for the implementation of placebo alcohol that successfully deceived participants in believing they had real liquor. Drawing on psychological and medical research showing that explicit suggestions increase expectancies associated with drug response (e.g., see Michael, Gary, \& Kirsch, 2012), the current study employed an experimental confederate, in addition to visual, olfactory, and taste cues recommended by earlier research (Breslin \& Sobell, 1999; Marlatt \& Rohsenow, 1980; Rohsenow \& Marlatt, 1981). For example, the confederate stated he/she "was definitely feeling [the alcohol]", and had a friend who "came home [from the study] buzzed." To our knowledge, no other study has used a confederate to increase placebo alcohol believability, but it was done with great success in the current experiment. Specifically, $90.5 \%$ of participants believed they were drinking real alcohol, according to experimenter ratings made after a lengthy funnel debrief. Comparisons on self-report questionnaire items between those who 
were and were not classified as deceived, suggest that our classification scheme was accurate. In particular, $96.2 \%$ of deceived participants, but only $7.1 \%$ of non-deceived participants, estimated their BAC at .01 or greater.

Previous research administering placebo alcohol has used a variety of methods to determine alcohol believability with highly varying results. At the end of the study, some researchers have asked participants whether they received alcohol, with the proportion of participants indicating "yes," and thereby considered deceived, varying from 59\% (Kreusch, Vilenne, \& Quertemont, 2013) to 63\% (Gilbertson, Prather, \& Nixon, 2010) to $100 \%$ (Abrams \& Wilson, 1979). In other studies, participants were asked how much alcohol they consumed (Morrison et al., 2012), or to estimate the alcoholic content of their beverage on an 11-point Likert Scale from $0 \%$ to $5 \%$ (Fillmore, Carscadden, \& Vogel-Sprott, 1998). All participants in these studies were considered deceived because everyone indicated consuming some amount of alcohol (Morrison et al) or having a beverage with an alcohol content above $0 \%$ (Fillmore et al). Other studies have examined alcohol believability at the group level. For instance, in one experiment, the mean-level response to a question assessing the number of standard drinks participants believed they consumed was reported (Sher, Bartholow, Peuser, Erickson, \& Wood, 2007). Sher and colleagues state: “The fact that those in the placebo group believed, on average, that they had consumed 2-3 drinks suggests that our cover story... was viable" (p. 372). In another study, the subjective intoxication ratings of participants were compared before and after receiving a placebo (Finnegan, Hammersley, \& Millar, 1995). On average, 
intoxication ratings increased, and this was viewed as lending credibility to the placebo administration.

Knight and colleagues (Knight, Barbaree, \& Boland, 1986) argued that most manipulation checks were too liberal because experimenter demands influence participant's responses. They conducted a two-part study assessing the role of experimenter demands on manipulation check replies. When the viability of placebo alcohol was initially assessed by asking, "Did you receive an alcoholic beverage," $92 \%$ said yes. In phase 2 of the study, after faking a computer malfunction that contained their "true" condition, the experimenter told participants that some people actually received a non-alcoholic beverage despite being told it contained alcohol. When participants were asked which beverage they thought they were given, only $58 \%$ believed it was alcohol.

On the one hand, we agree with Knight et al (1986) that demand characteristics likely play a role in traditional manipulation checks, thereby failing to capture the full range of non-deceived participants. In our study, everyone stated they consumed some portion of an alcoholic beverage. As such, if our manipulation check was identical to the one used by Morrison et al (2012), 100\% would be considered deceived. However, based on statements made during the debrief, this classification would be a clearly inappropriate for some subjects. For instance, one participant who reported having two alcoholic drinks stated, "I don't feel any different than before [I drank]. Maybe there wasn't alcohol."

Nonetheless, Knight et al.'s approach seems overly conservative. As discussed by Martin and Sayette (1991), this manipulation check might falsely categorize some 
participants as not deceived. During the study, it is likely that participants believed the alcohol was real, but responded to the second manipulation check in a manner consistent with not being deceived since the experimenter voluntarily suggested they may have received fake alcohol. As such, a middle ground between traditional manipulation checks, and the one used by Knight et al seems most appropriate. By using experimenter evaluations during a funnel debrief, and then comparing deceived and non-deceived participants on self-report measures, we think the manipulation check used in the present study achieves this goal.

As a whole, our deception rate is very good compared to past research, and excellent in light of the fact the manipulation check used here was more conservative than most. Furthermore, this was achieved even though $92.3 \%$ of participants were under legal drinking age. Since it would be illegal for us to actually provide them with alcohol, this group is presumably much more difficult to deceive. Upon hearing about the study, many participants expressed initial skepticism that we would be allowed to administer alcohol to minors. In fact, to our knowledge, the current experiment represents the very first attempt to provide real or placebo alcohol to underage participants $^{10}$, thereby allowing us to examine alcohol consumption among a high-risk group that has gone uninvestigated in experimental work.

The current study was also one of few to use placebo alcohol consumption as a dependent variable. This seems to have only been done twice in prior studies (Asp, 1977; Morrison et al., 2012). Typically, placebos are administered as an independent variable manipulation to isolate the psychological versus pharmacological effects of

\footnotetext{
${ }^{10}$ This excludes underage participants who knowingly receive a placebo during alcohol challenge studies.
} 
alcohol. However, given the logistical challenges associated with administering alcohol, as discussed above, researchers should consider using a placebo in this capacity. As long as participants believe they are drinking real alcohol, the validity of the study is not compromised.

\section{Strengths. Limitations, and Future Research}

One strength of the current study is that we were adequately powered to detect a medium-sized effect, despite having a high intraclass correlation (ICC $=.43)$, which hinders statistical power. The ICC observed here, however, is on par with other laboratory studies (Koordeman, Anschutz, \& Engels, 2012; Koordeman, Anschutz, van Baaren, \& Engels, 2010), and consistent with the broader literature. Specifically, one meta-observed an average weighted effect size for alcohol modeling of $d=0.97$ across 13 studies (Quigley \& Collins, 1999). Although a high ICC hurts statistical power, the large number of clusters $(k=54)$ increased power. Based on calculations from Optimal Design Software (Raudenbush et al., 2011), to achieve power of .80 with an ICC of .43, a sample size of 136, and cluster number of 54, one would need an approximate effect size of $\Delta=.56$. This study also achieved high ecological validity without compromising internal validity. As discussed at length above, the taste-test paradigm for alcohol administration commonly used in early work does not reflect alcohol consumption in the real world. By having participants in groups of 2-3 drink their beverage of choice ad lib in a naturalistic setting, the current study mirrored alcohol consumption outside of the laboratory while maintaining experimental control.

A major weakness of this study is that the anxiety manipulation may have induced performance anxiety. Future research should consider a stressor that more 
selectively targets social anxiety, perhaps by telling participants they have to interact with others in an awkward setting. This manipulation would more closely approximate the real-world, where college students sometimes drink before a party to alleviate anticipatory anxiety.

Another limitation is that, although participants could order as many drinks as desired, the amount of "alcohol" may have been viewed as limited. By only using 1.5 oz of liquor for every $9 \mathrm{oz}$. glass, some participants may have been motivated to drink for relief of negative affect, but assumed they wouldn't derive an anxiolytic effect from the alcohol we were serving, even if they consumed several glasses. During the debrief, many participants stated that they would typically pour several shots of liquor into one glass. As such, it appears that the alleged alcohol content of drinks in the current study was much weaker from those underage college students typically consume. Although a 1:5 ratio of alcohol to mixer is typically used in laboratory studies (Marlatt \& Rohsenow, 1980), college students who are not of age may be accustomed to making stronger beverages. Furthermore, these individuals presumably do not order alcohol in bars where one shot of liquor per drink is normative. Unfortunately, serving stronger drinks would probably lead to less placebo alcohol believability, so this may not be a viable option. However, future research may wish to consider using non-alcoholic beer as a placebo with underage students.

\section{Summary}

In the present study, anticipatory social anxiety was unrelated to alcohol use in a naturalistic setting, and no moderating effects were observed for trait social anxiety or neuroticism. These null results could be due to a social anxiety manipulation that 
was performance-based. Methodologically, after a careful debrief, we conservatively estimate that $90.5 \%$ of mostly underage participants believed they were drinking real alcohol after being administered a placebo. This finding is informative for the broader alcohol administration literature. 


\section{BIBLIOGRAPHY}

Abrams, K., Kushner, M.G., Medina, L., \& Voight, A. (2002). Self-administration of alcohol before and after a public speaking challenge by individuals with social phobia. Psychology of Addictive Behaviors, 16, 121-128. doi:

10.1037//0893-164X.16.2.121

Abrams, D.B., \& Wilson, G.T. (1979). Effects of alcohol on social anxiety in women: Cognitive versus physiological processes. Journal of Abnormal Psychology, 88, 161-173. Doi: 10.1037/0021-843X.88.2.161

Arnett, J.J. (2000). Emerging adulthood: A theory of development from the late teens through the twenties. American Psychologist, 55, 469-480.

Asp, D.R. (1977). Effects of alcoholics' expectation of a drink. Journal of Studies on Alcohol, 38, 1790-1795

Battista, S.R., Stewart, S.H., \& Ham, L.S. (2010). A critical review of laboratorybased studies examining the relationships of social anxiety and alcohol intake. Current Drug Abuse Reviews, 3, 3-22.

Bot, S.M., Engels, R.C.M.E., Knibbe, R.A., \& Meeus, W.H.J. (2007). Pastime in a pub: Observations of young adults' activities and alcohol consumption. Addictive Behaviors, 32, 491-504. doi:10.1016/j.addbeh.2006.05.015

Bot, S.M., Engels, R.C.M.E., \& Knibbe, R.A. (2005). The effect of alcohol expectancies on drinking behavior in peer groups: Observations in a naturalistic setting. Addiction, 100, 1270-1279. doi: 10.1111/j.13600443.2005.01152.x

Breslin, F.C., \& Sobell, S.L. (1999). Alcohol administration methodology 1994-1995: 
What researchers do and do not report about subjects and dosing procedures. Addictive Behaviors, 24, 509-520. http://dx.doi.org/10.1016/S03064603(99)00002-7

Buckner, J.D., Schmidt, N.B., \& Eggleston, A.M. (2006). Social anxiety and problematic alcohol consumption: The mediating role of drinking motives and situations. Behavior Therapy, 37, 381-391.

Buckner , J.D., \& Turner, R.J. (2009). Social anxiety disorders as a risk factor for alcohol use disorders: A prospective examination of parental and peer influences. Drug and Alcohol Dependence, 100, 128-137.

Doi:10.1016/j.drugalcdep.2008.09.018

Bushman, B.J., Giancola, P.R., Parrott, D.J., \& Roth, R.M. (2012). Failure to consider future consequences increases the effects of alcohol on aggression. Journal of Experimental Social Psychology, 48, 591-595. doi:10.1016/j.jesp.2011.11.013.

Clerkin, E.M., Barnett, N. (2012). The separate and interactive effects of drinking motives and social anxiety symptoms in predicting drinking outcomes. Addictive Behaviors, 37, 674-677. Doi: 10.1016/j.addbeh.2012.01.005

Collins, R.L., Parks, G.A., \& Marlatt, G.A. (1985). Social determinants of alcohol consumption: The effects of social interaction and model status on the selfadministration of alcohol. Journal of Consulting and Clinical Psychology, 53, 189-200. doi: 10.1037/0022-006X.53.2.189

Cooper, M.L. (1994). Motivations for alcohol use among adolescents: Development and validation of a four-factor model. Psychological Assessment, 6, 117-128. Doi: 10.1037/1040-3590.6.2.117 
Corcoran, K.J., \& Parker, P.S. (1991). Alcohol expectancy questionnaire tension reduction scale as a predictor of alcohol consumption in a stressful situation. Addictive Behaviors, 16, 129-137.

Cox, W.M., \& Klinger E. A motivational model of alcohol use. (1988) Journal of Abnormal Psychology, 97, 168-180. doi: 10.1037//0021-843X.97.2.168.

De Wit, H., Soderpalm, A.H.V., Nikolayev, L., \& Young, E. (2003). Effects of acute social stress on alcohol consumption in healthy subjects. Alcoholism: Clinical andExperimental Research, 27, 1270-1277. doi: 0.1097/01.ALC.0000081617.37539.D6

Fillmore, M.T., Carscadden, J.L., Vogel-Sprott, M. (1998). Alcohol, cognitive impairment and expectancies. Journal of Studies on Alcohol, 59, 174-179.

Finnigan, F., Hammersley, R., \& Millar, K. (1995). The effects of expectancy and alcohol on cognitive-motor performance. Addiction, 90, 661-672.

Gilbertson, R., Prather, R., \& Nixon, S.J. (2010). Acute alcohol administration and placebo effectiveness in older moderate drinkers: Influences on cognitive performance. Journal of Studies on Alcohol and Drugs, 71, 345-350.

Gordh, A.H.V.S., Brkic, S., \& Soderpalm, B. (2011). Stress and consumption of alcohol in humans with a Type 1 family history of alcoholism in an experimental laboratory setting. Pharmacology, Biochemistry, and Behavior, 99, 696-703. doi: doi:10.1016/j.pbb.2011.05.028

Gronkjaer, M., Vinther-Larsen, M., Curtis, T., Gronbaek, M., \& Norgaard, M. (2010). Alcohol use in Denmark: A descriptive study on drinking contexts. Addiction Research and Theory, 18, 359-370. doi: 10.3109/16066350903145056 
Ham, L.S., Bonin, M., \& Hope, D.A. (2007). The role of drinking motives in social anxiety and alcohol use. Journal of Anxiety Disorders, 21, 991-1003. doi:10.1016/j.janxdis.2006.10.014

Ham, L.S., Carrigan, M.H., Moak, D.H., \& Randall, C.L. (2005). Social anxiety and specificity of positive alcohol expectancies: Preliminary findings. Journal of Psychopathology and Behavioral Assessment, 27, 115-121. doi: $10.1007 / \mathrm{s} 10862-005-5385-\mathrm{x}$

Ham, L.S., \& Hope, D.A. (2005). Incorporating social anxiety into a model of college student problematic drinking. Addictive Behavior, 30, 127-150. 127-150. doi:10.1016/j.addbeh.2004.04.018.

Ham, L.S., \& Hope, D.A. (2006). Incorporating social anxiety into a model of college problem drinking: Replication and extension. Psychology of Addictive Behaviors, 20, 348-355. doi:10.1037/0893-164X.20.3.348

Higgins, R.L, \& Marlatt, G.A. (1973). Effects of anxiety arousal on the consumption of alcohol by alcoholics and social drinkers. Journal of Consulting and Clinical Psychology, 41, 426-433. doi: 10.1037/h0035366

Higgins, R.L., \& Marlatt, G.A. (1975). Fear of interpersonal evaluation as a determinant of alcohol consumption in male social drinkers. Journal of Abnormal Psychology, 84, 644-651. Doi: 10.1037/0021-843X.84.6.644

Holroyd (1978). Effects of social anxiety and social evaluation on beer consumption and social interaction. Journal of Studies on Alcohol, 39, 737-744.

Horn, J. L. (1965). A Rationale and Test For the Number of Factors in Factor Analysis. Psychometrika, 30, 179-85. Doi: 10.1007/BF02289447 
Hull, J.G., \& Young, R.D. (1983). Self-consciousness, self-esteem, and success-failure as determinants of alcohol consumption in male social drinkers. Journal of Personality and Social Psychology, 44, 1097-1109. doi: 10.1037/00223514.44.6.1097

John, O.P., Donahue, E.M., \& Kentle, R.L. (1991). The Big Five Inventory-Versions $4 a$ and $4 b$. Berkeley, CA University of California, Berkeley, Institute of Personality and Social Research.

Johnston, L. D., O’Malley, P. M., Bachman, J. G., \& Schulenberg, J. E. (2012). Monitoring the Future national survey results on drug use, 1975-2011: Volume II, College students and adults ages 19-50. Ann Arbor: Institute for Social Research, The University of Michigan.

Kahler, C.W., Strong, D.R., \& Read, J.P. (2005). Toward efficient and comprehensive measurement of the alcohol problems continuum in college students: The Brief Young Adult Alcohol Consequences Questionnaire. Alcoholism: Clinical and Experimental Research, 29, 1180-1189. doi:

10.1097/01.ALC.0000171940.95813.A5

Kessler, R.C., Crum, R.M., Warner, L.A., Nelson, C.B., Schulenberg, J., \& Anthony, J.C. (1994). Lifetime co-occurrence of DSM-III-R Alcohol Abuse and Dependence with other psychiatric disorders in the National Comorobitiy Survey. Archives of General Psychiatry, 54, 313-321.

Kidorf, M., \& Lang, A.R. (1999) Effects of social anxiety and alcohol expectancies on stress-induced drinking (1999). Psychology of Addictive Behaviors, 13, 134142. Doi: 10.1037/0893-164X.13.2.134 
Knight, L.J., Barbaree, H.E., \& Boland, F.J. (1986). Alcohol and the balanced-placebo design: The role of experimenter demands in expectancy. Journal of Abnormal Psychology, 95, 335-340.

Koordeman, R., Anshutz, D.J., \& Engels, R.C.M.E. (2012). The effect of alcohol advertising on immediate alcohol consumption in college students: An experimental study. Alcoholism: Clinical and Experimental Research, 36, 874880. Doi: 10.1111/j.1530-0277.2011.01655.x

Koordeman, R., Anschutz, D.J., van Baaren, R.B., \& Engels, R.C.M.E. (2010). Effects of alcohol portrayals in movies on actual alcohol consumption: An observational experimental study. Addiction, 106, 547-554. Doi: $10.1111 / \mathrm{j} .1360-0443.2010 .03224 . \mathrm{x}$

Kreusch, F., Vilenne, A., \& Quertemont, E. (2013). Assessing the stimulant and sedative effects of alcohol with explicit and implicit measures in a balanced placebo design. Journal of Studies on Alcohol and Drugs, 74, 923-930.

Lang, A.R., Pelham, W.E., Johnston, C., \& Gelernter, S. (1989). Journal of Abnormal Psychology, 98, 294-299. doi: 10.1037/0021-843X.98.3.294

Larsen, H., Overbeek, G., Granic, I., \& Engels, R.C.M.E. (2010). Imitation of alcohol consumption in same-sex and other-sex dyads. Alcohol \& Alcoholism, 45, 557562. doi: 10.1093/alcalc/agq053 doi: 10.1093/alcalc/agq053

Larsen, H., Overbeek, G., Granic, I., \& Engels, R.C.M.E. (2012). The strong effect of other people's drinking: Two experimental observational studies in a real bar. The American Journal of Addicitons, 21, 168-175. doi: 10.1111/j.15210391.2011.00200.x. 
Larsen, H., Engels, R.C.M.E., Granic, I., \& Huizink, A.C. (2013). Does stress increase imitation of drinking behavior An experimental study in a (semi-) naturalistic context. Alcoholism: Clinical and Experimental Research, 37, 477-483 10.1111/j.1530-0277.2012.01942.x

Leeman, R.F., Corbin, W.R., \& Fromme, K. (2009). Craving within session drinking behavior following placebo. Personality and Individual Differences, 46, 693698. doi:10.1016/j.paid.2009.01.024

Littlefield, A.K., Sher, K.J., \& Wood, P.K. (2010). A personality-based description of maturing out of alcohol problems: Extension with a Five-Factor model and robustness to modeling challenges. Addictive Behaviors, 35, 948-954. doi:10.1016/j.addbeh.2010.06.008

Littlefield, A.K., Sher, K.., \& Wood, P.K. (2009). Is "Maturing out of problematic alcohol involvement related to personality change? Journal of Abnormal Psychology, 118, 360-374. doi: 10.1037/a0015125.

Maas, C.J.M., \& Hox, J.J. (2004). The influence of violations of assumptions on multilevel parameter estimates and their standard errors. Computational Statistics \& Data Analysis, 46, 427-440. doi:10.1016/j.csda.2003.08.006

Martin, C.S., \& Sayette, M.A. (1993). Experimental design in alcohol administration research: Limitations and alternatives in the manipulation of dosage-set. Journal of Studies on Alcohol, 54, 750-761.

Marlatt, G.A., \& Rohsenow, D.J. (1980). Cognitive processes in alcohol use: Expectancy and the balanced placebo design. In N. Mello (Ed.) Advances in substance abuse (Vol. 1, pp. 159-199). Greenwhich, CT: JAI Press 
Mattick, R.P., \& Clarke, J.C. (1988). Development and validation of measures of social phobia scrutiny fear and social interaction anxiety. Behavior Research and Therapy, 36, 455-470. doi: 10.1016/S0005-7967(97)10031-6.

Marlatt, G.A., Kosturn, C.F. \& Lang, A.R. (1975). Provocation to anger and opportunity for retaliation as determinants of alcohol consumption in social drinkers. Journal of Abnormal Psychology, 84, 652-659. doi: 10.1037/0021$843 X .84 .6 .652$

Marteau, T.M., \& Bekker, H. (1992). The development of a six-item short-form of the state scale of the Spielberger State-Trait Anxiety Inventory (STAI). British Journal of Clinical Psychology, 31, 301-306.doi:

10.1111/j.2044-8260.1992.tb00997.x

Michael, R.B., Garry, M., \& Kirsch, I. (2012). Suggestion, cognition, and behavior. Current Directions in Psychological Science, 21, 151-156. Doi: $10.1177 / 0963721412446369$

Morrison, P.M., Noel, N.E., \& Ogle, R.L. (2012). Do angry women choose alcohol? Addictive Behaviors, 37, 908-813. Doi:10.1016/j.addbeh.2012.03.018.

Naragon-Gainey, K., \& Watson, D. (2011). Clarifying the dispositional basis of social anxiety: A hierarchical perspective. Personality and Individual Differences, 50, 926-934. doi:10.1016/j.paid.2010.07.012.

National Institute on Alcohol Abuse \& Alcoholism. Administering Alcohol in Human Studies. Retrieved from: http://www.niaaa.nih.gov/research/guidelines-andresources/administering-alcohol-human-studies

Nesic, J., \& Duka, T. (2006). Gender specific effects of a mild stressor on alcohol cue 
reactivity in heavy social drinkers. Pharmacology, Biochemistry, and Behavior, 83, 239-248. Doi: 10.1016/j.pbb.2006.02.006

Norberg, M.N., Norton, A.R., \& Oliver, J (2009). Refining measurement in the study of social anxiety and student drinking: Who you are and why you drink determines your outcomes. Psychology of Addictive Behaviors, 23, 586-597. doi: $10.1037 / \mathrm{a} 0016994$

Malouff, J.M., Thorsteinsson, E.B., Rooke, S.E., \& Schutte, N.S. (2007). Alcohol involvement and the five-factor model of personality: A meta-analysis. Journal of Drug Education, 37. doi: 10.2190/DE.37.3.d

McNair (1996). Alcohol use and stress in women: The role of prior vs. anticipated stressors. Journal of Psychopathology and Behavioral Assessment, 18, 331345. doi: 10.1007/BF02229139

Park, C.L., \& Levenson, M.R. (2002). Drinking to cope among college students: prevalence, problems, and coping processes. Journal of Studies on Alcohol, 63 486-497.

Patil, V.H., Singh, S.N., Mishra, S., \& Donavan, D.T. (2007). Parallel Analysis Engine to Aid Determining Number of Factors to Retain [Computer software]. Available from: http://smishra.faculty.ku.edu/parallelengine.htm

Pedersen, E.R., LaBrie, J.W., Kilmer, \& J.R. (2009). Before you slip into the night, you'll want something to drink: Exploring the reasons for prepartying behavior among college student drinkers. Issues in Mental Health Nursing, 30, 354-363.doi: 10.1080/01612840802422623

Pelham, W.E., Lang, A.R., Atkeson, B., Murphy, D.A., Gngy, E.M., Greiner, A.R., 
... Greenslade, K.E. (1997). Effects of deviant child behavior on parental distress and alcohol consumption in laboratory interactions. Journal of Abnormal Child Psychology, 25, 413-424. doi: 10.1023/A:1025789108958

Perkins, H.W. (1999). Stress-motivation drinking in collegiate and postcollegiate young adulthood: Life course and gender patterns. Journal of Studies on Alcohol, 60, 219-227.

Peters, L., Saunderland, M., Andrews, G., Rapee, RM., \& Mattick, R.P. (2012). Development of a short form Social Interaction Anxiety (SIAS) and Social Phobia Scale (SPS) using nonparametric item response theory: The SIAS-6 and SPS-6. Psychological Assessment, 24, 66-76. doi: 10.1037/a0024544

Peterson, J.B., Morey, J., \& Higgins, D.M. You drink, I drink: Alcohol consumption, social context and personality. Individual differences Research, 3, 50-58.

Plebani, J.G., Ray, LA., Morean, M.E., Corbin, W.R., MacKillop, J., Amlung, M., \& King, A.C. (2012). Human laboratory paradigms in alcohol research. Alcoholism: Clinical and Experimental Research, 36, 972-983. doi: 10.1111/j.1530-0277.2011.01704.x

Quigley, B.M., \& Collins, R.L. (1999). The modeling of alcohol consumption: A meta-analytic review. Journal of Studies on Alcohol, 60, 90-98.

Rammstedt, B., \& John, O.P. (2007). Measuring personality in one minute or less: A 10-item short version of the Big Five Inventory in English and German. Journal of Research in Personality, 41, 203-212. doi:10.1016/j.jrp.2006.02.001

Raudenbush, S.W., Spybrook, J., Congdon, R., Liu, X., Martinez, A., Bloom, H., \& 
Hill, C. (2011). Optimal Design Software for Multi-level and Longitudinal Research (Version 3.01) [Software]. Available from http://sitemaker.umich.edu/group-based/optimal_design_software

Rohsenow, D.J., \& Marlatt, G.A. (1981). The balanced placebo design: Methodological considerations. Addictive Behaviors, 6, 107-122. Doi: $10.1016 / 0306-4603(81) 90003-4$

Safren, S.A., Heimberg, R.G., Horner, K.J., Juster, H.R., Schneier, F.R., \& Liebowitz, M.R. (1999). Factor structure of social fears: The Liebowitz Social Anxiety Scale. Journal of Anxiety Disorders, 13, 253-170.

Schry, A.R., \& White, S.W. (2013). Understanding the relationship between social anxiety and alcohol use in college students: A meta-analysis. Addictive Behaviors, 38, 2690-2706. http://dx.doi.org/10.1016/j.addbeh.2013.06.014

Sher, K.J., Bartholow, B.D., Peuser, K., Erickson, D.J., \& Wood, M.D. (2007). Stressresponse-dampening effects of alcohol: Attention as a mediator and moderator. Journal of Abnormal Psychology, 116. Doi:10.1037/0021-843X.116.2.362.

Sher, K.J., Bylund, D.B., Walitzer, K.S., Hartmann, J., \& Ray-Prenger, C. (1994). Platelet Monoamine Oxidase (MAO) activity: Personality, substance use, and the stress-response-dampening effect of alcohol. Experimental and Clinical Psychopharmacology, 2, 53-81. 10.1037/1064-1297.2.1.53

Sher, K. J., Trull, T. J., Bartholow, B. D., \& Vieth, A. (1999). Personality and alcoholism: Issues, methods, and etiological processes. In K. E. Leonard, \& H. T. Blane (Eds.), Psychological theories of drinking and alcoholism (pp. 54105). (2nd Ed.). New York: Guilford Press. 
Singer, J.D. (1998). Using SAS PROC MIXED to fit multilevel models, and individual growth models. Journal of Educational and Behavioral Statistics, 4, 323-355. Doi: 10.3102/10769986023004323

Spielberger, C. D., Gorsuch, R. L., Lushene, R., Vagg, P. R., \& Jacobs, G. A. (1983). Manual for the State-Trait Anxiety Inventory. Palo Alto, CA: Consulting Psychologists Press.

Terlecki, M.A., Buckner, J.D., Larimer, M.E., \& Copeland, A.L. (2011). The role of social anxiety in a brief alcohol intervention for heavy-drinking college students. Journal of Cognitive Psychotherapy: An International Quarterly, 25, 7-21. doi: 10.1891/0889-8391.25.1.7

Tucker, J.A., Vuchinich, R.E., Sobell, M.B., \& Miasto, S.A. (1980). Normal drinkers' alcohol consumption as a function of conflicting motives induced by intellectual performance stress. Addictive Behaviors, 5, 171-178.

Thomas, S.E., Bacon, A.K., Randall, P.K., Brady, K.T., \& See. R.E. (2011). An acute psychosocial stressor increases drinking in non-treatment-seeking alcoholics. Psychopharmacology, 218, 19-28. doi: 10.1007/s00213-010-2163-6

Thomas, S.E., Randall, C.L., \& Carrigan, M.H. (2003). Drinking to cope in socially anxious individuals: A controlled study. Alcoholism: Clinical and Experimental Research, 27, 1937-1943. Doi:

10.1097/01.ALC.0000100942.30743.8C

van Schoor, G., Bot, S.M., \& Engels, R.C.M.E. (2008). Alcohol drinking in young adults: The predictive value of personality when peers come around. European Addiction Research, 14, 125-133. doi: 10.1159/000130416 
Wood, M.D. (1996). Alcohol and aggression: An examination of the roles of cognitive functioning and personality. (Unpublished doctoral dissertation): University of Missouri-Columbia, Columbia, MO

Zuckerman, M., Kuhlman, D.M., \& Camac, C. (1988). What lies beyond E and N?

Factor analyses of scales believed to measure dimensions of personality.

Personality Processes and Individual Differences, 54, 96-107. doi:

10.1037/0022-3514.54.1. 